\title{
Expertise and Its Tensions
}

\author{
Maria Åkerman \\ VTT Technical Research Centre of Finland \\ Jaakko Taipale \\ Faculty of Social Sciences, University of Helsinki, Finland \\ Sampsa Saikkonen \\ Faculty of Social Sciences, University of Helsinki, Finland \\ Ismo Kantola \\ Department of Social Research, University of Turku, Finland/ikantola@utu.fi \\ Harley Bergroth \\ Department of Social Research, University of Turku, Finland
}

While writing this editorial in the end of March 2020, the world is struggling to contain the virus SARS-CoV-2, which has caused the most severe pandemic since the beginning of the $20^{\text {th }}$ century and the Spanish flu. Despite regular warnings of an aggressive pandemic in a number of expert-driven reports in recent decades, it seems that the coronavirus outbreak hit policymakers in most countries by surprise. The media now constantly reports on the efforts of epidemiologists and medical experts to get to know the characteristics of the yet poorly known new coronavirus. Headlines also often highlight how policy makers, public health experts and economists discuss and weigh various societal measures in order to mitigate the social and economic consequences of the outbreak. The contested and negotiated character of expertise becomes visible in how the adopted strategies differ between countries and how people with various backgrounds claim and gain expert positions in pandemic governance in different public forums.

The current pandemic is clearly a textbook example of a wicked problem in which "facts are uncertain, values in dispute, stakes high and decisions urgent" (Funtowicz and Ravetz, 1993: 744). Should we go by the now popular metaphor of a war, the struggle against COVID-19 is taking place within many different regimes of knowledge and the global line of defence is not always uniform. Broadly speaking, the pandemic highlights the multifocality of expertise in contemporary globalised and interconnected societies. It seems likely that the number of societal dilemmas characterised by contested and/or dispersed expertise will continue to increase in the future due to a variety of pressing global issues such as ongoing global environmental changes, the related energy transition and other types of sustainability challenges, novel modes of citizen 
engagement in research and innovation, and the proliferation of debates around health and medicine. The aim of this special issue is to open up discussions on the variety of approaches that STS studies provide to strengthen the understanding of the changing role of expertise in shaping the everyday life and futures of our society in this evolving context.

The question of how, and whose, knowledge and expertise are recognised and mobilised in societal processes has been one of the key interests of STS studies of expertise during recent decades. At the level of policy making, on the one hand, the role of experts in shaping policy agenda and framing policy issues has been recognised particularly in traditionally expert driven policy fields such as environmental (e.g. Turnhout et al., 2019) and health (e.g. Smith, 2013; Maybin, 2016) policy. On the other hand, existing science- policy gaps might explain the failures in addressing urgent environmental problems including climate change and loss of biodiversity. These gaps have been argued to result from both the inability of policy makers to make use of scientific knowledge and engage with it in decision-making (Bradshaw and Borchers, 2000; Sharman and Holmes, 2010) and the lacking interactional skills of scientists in articulating the policy relevance of their knowledge (Rapley, 2012).

The emphasis put on the need to continuously articulate and negotiate the societal relevance of scientific expertise highlights the relational nature of expertise more generally. Expertise is not a quality that can be gained solely through education, experience or institutional position. Rather, expert positions are always gained in relation to context specific expectations and needs of knowledge and skills (Lynch, 2014). Therefore, different types of expertise are recognised in varying social contexts and lay experts sometimes acquire considerable epistemic authority in addition to, or even over, institutionally acknowledged professional experts (e.g. Epstein, 1996; Reed et al., 2014; Collins, 2014; Irwin et al., 2018; Saikkonen, 2019). The multiplicity of different types of experts and expertise with different backgrounds, approaches and ways to frame, justify and communicate issues makes the distinction between an expert and non-expert blurry and changing. This blurriness furthermore underlines the importance of understanding the situated constitution of expertise (e.g. Coopmans and Button, 2014; Taipale, 2019).

The field of STS has productively illuminated the social and cultural aspects of expertise in a variety of contexts, but the focus has considerably been on specific theoretical issues, such as the classic issue of expert-lay relations (e.g. Wynne, 1992, 1996; Epstein, 1996), and debates, such as that between realist and relational approaches to expertise (e.g. Collins and Evans, 2002, 2003; Jasanoff, 2003; Rip, 2003; Wynne, 2003;). While the scope of STS has by no means been limited only to these issues, there is certainly room for novel theoretical and empirical viewpoints in expertiserelated research, especially if STS is to secure its position as the vanguard of the social study of expertise.

One fruitful avenue, which the articles of Francois-Joseph Daniel as well as Line Hillersdal, Astrid Petersen, Bjarke Oxlund and Birgitte Bruun in this special issue importantly explore and contribute to, is the study of the affective aspects and dimensions of expertise. Although there is mounting interest in the affective and emotional in the humanities and social sciences more generally (e.g. Clough and Halley 2007; Wetherell, 2012), and increasingly also within STS in different contexts (e.g. Lorimer, 2008; Myers, 2008; Davies, 2014; Kerr and Garforth, 2016; Lindén, 2019), examinations of affects with respect to expertise are lacking in STS. As the aforementioned articles in this special issue demonstrate, such examinations enhance our understanding about the various ways in which expertise is produced, operates, and is negotiated in different contexts, and how tensions in expertise and among experts emerge.

The articles in this issue also suggest and present other directions for broadening the STS scope on expertise. For example, there is a growing interest in following and studying new types of communities engaged in generation and sharing of knowledge and construction of technologies, such as hackerspace communities (e.g. Kera, 2012; Maxigas, 2012; Davies, 2017). In this vein, Eeva Berglund and Cindy Kohtala draw attention to new types of grassroots communities as sites of inquiry in studying expertise. Furthermore, 
they highlight the communal, collective nature of the emergence of expertise in such communities. As the communal nature of knowledge is one of the foundational notions in the field since the early SSK (e.g. Barnes and Bloor, 1982), it is worthwhile to revisit the idea of communality in scrutinising the character and emergence of expertise and expert knowledges. Related to this, Claudia Egher's article highlights the role of the medium and mediators in displaying and articulating expertise. The relevance of the medium, arenas and platforms together with mediating actors has been recently emphasised in the social studies of expertise (also e.g. Saikkonen, 2019) and this emphasis will most likely gain importance in the field in the future.

We conclude this guest editorial with short summaries of the seven contributions to this special issue, which shed light on how expertise is constituted in different contexts as a situated practice. This emphasis guides us to pay attention on the socio-material context in which expertise is claimed and performed, as well as to recognise the embodied nature of expertise in terms of personal skills, craft, and affective engagement. Furthermore, the articles explore the connections between particular societal goals and norms, and related recognition of expertise.

Egher discusses how the Internet as a medium of communication shapes the relations between medical professionals and patients. She examines three highly popular bloggers, who combine their situated experience of living with bi-polar disorder with their understanding of specialised medical knowledge, and communicate their ideas to the broader public in the blogosphere. As a result of this activity, and by and large because of the new communicative medium that allows for explication and broad dissemination of patient experience, the three bloggers Egher examines can be understood as a new category of stakeholders that she calls expert online mediators. These mediators are highly influential in translating medical/scientific knowledge to the relevant lay audience or community, and they also provide medical professionals new avenues for collaboration.

Drawing from studies of expertise, Egher employs and elaborates on the concept of interactional expertise (Collins and Evans, 2002) in developing her understanding of what the bloggers do. She expands the notion of interactional expertise by emphasising the relevance of the medium of communication as well as by focusing on the bi-directional character of interactional expertise, i.e., the mediating work. Thus, Egher implies that the relevance of the medium has been somewhat overlooked by Collins and Evans, and goes on to discuss how the internet has shaped the way the bloggers display their interactional expertise, while she also identifies some important challenges that internet poses to performing interactional expertise. Egher also claims that interactional experts can have more substantial exchanges with scientists/professionals (the so-called contributory experts, see Collins and Evans, 2007), than what Collins and Evans have previously envisaged, as shown by her analysis of the illness bloggers. She concludes by discussing the bloggers as entrepreneurial selves. Egher also problematises their influence in the patient community, their effect on hierarchies between professionals and lay people, and also their possible challenge to the authority and trust towards medicine and available treatments.

In their article William Clark Cook, Esther Turnhout and Séverine van Bommel investigate Forest Stewardship Council (FSC) auditor trainings. By analysing empirical materials gathered from the trainings through participant observation and unstructured interviews, the authors specifically focus to make explicit how the trainees are taught, and learn to become, experts in FSC auditing. Cook, Turnhout and van Bommel highlight the paradoxical aspect of how experts need to follow rules and be objective, but how expertise is also about mastering a craft that inevitably involves subjectivity. Their article therefore takes interest in the issue of how the alignment of objectivity and subjectivity through expertise takes place in the auditor training. As a theoretical perspective, the authors employ a dramaturgical lens and draw on Erving Goffman's (1959) concept of performance and Heather Douglas' (2004) notion of three modes of objectivity (object-oriented, value-oriented, and process-oriented objectivity) to scrutinise how objectivity is performed in the trainings and how it is taught for the trainees to be performed as FSC auditing experts. Building 
on Goffman's notion of a performance involving a 'frontstage' and a 'backstage' the authors also pay attention to the issue of how successfully performing objectivity in the frontstage as an auditing expert depends on subjective intuitions and values that belong to the mastery of the auditing as a craft that has to be held backstage.

Based on their analysis Cook, Turnhout and van Bommel highlight that while objectivity is considered fundamental to auditing in the trainings, the trainees are also taught how objectivity and interpretation can be simultaneously performed, and are therefore co-supportive of each other, in properly performing the auditing. Moreover, in the concluding discussion they also valuably raise and discuss the more general theoretical issue of how their results indicate how instead of approaching expertise in dichotomous terms either as a performance or as a real ability (e.g. Collins and Evans, 2007) it is important to recognise and study how expertise encompasses both of these aspects. Regarding this, the authors highlight how their study makes explicit that rather than there being a tension between these aspects in forest management certification auditing both the performance of being an auditor and the impact of being an auditor are important parts of the training of FSC auditing experts. Finally, the authors emphasise that recognising the role of subjectivity, values and interpretation in audits is important to understand how objectivity is produced in practice, and that this also enables auditor trainings to be more open and reflect about the values constituting auditing.

In his contribution to this special issue, Daniel investigates resident sniffing teams set up to assess odorous pollution in two urban areas in France where domestic waste treatment biogas production plants have been opened. Daniel bases his analysis on a series of interviews with members of these sniffing teams and builds theoretically on the affective turn in the social study of science. He specifically scrutinises the affective dimensions of how the sniffing teams, as kinds of lay-expert collectives who do odour sensing in an open air environment, get involved in such activity and work to produce observations of odorous pollution. In his article, Daniel therefore especially strives to make explicit the ways in which emotional context plays a role for the emergence of the collective sensory expertise of the sniffing teams. Daniel demonstrates how emotions colonise the daily sniffing work and how the differences in sensitivity among the participants forms challenges regarding the data collection work of the teams. He points out how individuals in the sniffing teams can be affected differently by the smells, and how, for some sniffers, negative emotions emerging can come to influence the reporting of the sniffing as there is a need to maintain attention in the work to an element of their actual living environment that is unpleasant.

In the concluding discussion Daniel further highlights the role of affects in the making of sensory expertise. He points out how the participants of the sniffing teams need to develop an "ethic" of sensing, centered on the sniffers' own feeling, which brings to the fore the affective inner states of the sniffers and those who they represent, the other local residents. Moreover, Daniel emphasises how the development of this sensibility produces a local affective ontology and how the sniffing teams therefore also enable the nuisance to exist within institutional procedures. Daniel also finally draws attention to the democratising potential of utilising the kind of participatory tools such as sniffing teams as they allow for people's sensorial and affective living environments to be better taken into account as industries, cities and infrastructures are developed.

The contribution by Hillersdal, Petersen, Oxlund and Bruun, titled "Affect and Effect in Interdisciplinary Research Collaboration", investigates the working of interdisciplinary research collaboration through a focus on affective tensions emerging in these collaborations. Having worked in two separate interdisciplinary research projects in Denmark, the authors employ an ethnographic approach and draw from field notes, interviews and textual materials in order to observe and analyse the affective landscape of collaborative research work. One of the crucial points here is that the notion of affect contributes to social studies of science as it illuminates how scientific knowledge is produced and made in practice through embodied modes of being and communication. The authors base their article in previous 
studies on interdisciplinary collaboration and specifically 'choreography of affect' in scientific knowledge production. In addition, drawing from Helen Verran's (1999) work they point to the fluid ontology of research objects such as pain or appetite, as researchers from different fields negotiate and enact their objects of study through affective practices of, for example, suspicion, jokes, laughter and awkwardness.

The authors conclude that while interdisciplinary research is often marked by affective tensions stemming from internal differences and clashes of disciplinary expertise, such tensions can become productive of 'new connections between people and problems'. As affectively charged moments bring forth the instability of knowledge, they may also be understood as promoting an innovative and reflexive mode of scientific knowledge production.

Bonno Pel's and Julia Backhaus' article "Realizing the Basic Income: Competing Claims to Expertise in Transformative Social Innovation" looks into how 'utopian' and yet-to-be-realised policy practices such as the implementation of universal and unconditional basic income (BI) question deeply ingrained modes of knowing about the world, and are thus revealed as field in which tensions on expertise manifest particularly strongly. At the center of their paper is the concept of BI'realisation' that refers to the dynamics of how the advocacy on $\mathrm{BI}$ requires active work on both scientific and political domains of knowledge and how this work is distributed into vast networks of scientific, political and non-governmental actors. By drawing on interviews and observations with relevant actors, they trace overlapping yet in some ways also distinct waves of BI realisation, and tease out a 'fourth wave' of Bl advocacy, in which $\mathrm{Bl}$ advocacy employs experimentdriven and reflective strategies in its claims for expertise. Developing this argument, the authors present analytical observations of how various phenomena such as crowdfunding projects, the flow of information in the Internet as well as civic initiatives and petitions may shape the debate on, and knowledge of, Bl. They conclude that "the case of $\mathrm{Bl}$ advocacy is particularly revelatory for the politics of expertise that current social innovation initiatives are inevitably engaged in" and discuss how $\mathrm{Bl}$ advocacy practices tend to tread a messy path between alternative-spirited counter-expertise and evidence-based 'expertocracy game'.

Berglund \& Kohtala's article is a participant ethnographic study of DIY-activism and 'dirt way' learning in DIY-activist communities, which involves dealing with and being engaged in the use of contingent concepts and messy practices. A backdrop note to both the article and the emergence of its object of research pinpoints that the trustworthiness of expertise has suffered recently (e.g. due to the mainstream experts' disputes about sustainability). The background of their study is the critique of mainstream expertise's way to form closures of knowledge by 'meaningful simplifications' (Collins and Evans, 2002; Åkerman, 2016). Maker communities do have the same concept of expertise. However, they differ from the mainstream understanding of expertise in questioning its commitment to the social practices that serve capitalism driven consumerism and in perceiving knowledge making as practices of consciously designing futures under a likely danger combined with unacknowledged ignorance (Jasanoff, 2016). In the post-enlightenment ontology more or less present in DIYactivism, angry mountains and a higher God whose intentions remain unknowable, nevertheless, can affect human affairs. In the authors' ethnography, knowledge and ignorance jostle against each other in a fruitful way, reflecting their fuzzy object of research. To their credit, authors discuss succinctly 'socially robust' knowledge of the science policy discourse and its links to problem solving devoted exclusively to cognitive capitalism.

Sophy Bergenheim's study discusses how the Finnish Population and Family Welfare League (Väestöliitto) constructed and developed its expertise, and how the league changed from an influential interest organisation into a concrete housing policy actor. The author shows that this development started from the construction of a social problem, namely, the recognition of lower socio-economical classes' risks related to defective housing that the pioneers of Väestöliitto coined 'barracks'. The solution that came around in the 
development of expertise of the organisation was to build so-called garden cities for the imperiled population. The article narrates the development of new knowledge - about how ideas and orientation developed into new practices, and how the use of modern architecture and modern construction industry fed in to the development of an active and effective housing policy expertise.
To round up, the guest editorial board wishes to thank all contributors to this special issue. It is our belief that this collection of papers provides an interesting contribution to social studies of expertise. The on-going global changes and their local implications will undoubtedly generate an increasing need to study the contestation, negotiation and various roles of expertise. It is our hope that ideas presented in this special issue can inform some of those future studies. 


\section{References}

Barnes B and Bloor D (1982) Relativism, Rationalism and the Sociology of Knowledge. In: Hollis M and Lukes S (eds) Rationality and Relativism. Oxford: Basil Blackwell, pp. 21-47.

Bradshaw GA and Borchers JG (2000) Uncertainty as Information Narrowing the Science-policy Gap. Conservation Ecology 4(1).

Clough P and Halley J (eds) (2007) The Affective Turn: Theorizing the Social. Durham, NC: Duke University Press.

Collins H (2014) Are we all scientific experts now? Cambridge: Polity Press.

Collins $\mathrm{H}$ and Evans R (2002) The third wave of science studies: Studies of expertise and experience. Social Studies of Science 32(2): 235-296.

Collins H and Evans R (2003) King Canute meets the beach boys: Responses to the third wave. Social Studies of Science 33(3): 435-452.

Collins H and Evans R (2007) Rethinking Expertise. Chicago: University of Chicago Press.

Coopmans C and Button G (2014) Eyeballing expertise. Social Studies of Science 44(5): 758-785.

Davies SR (2014) Knowing and loving: Public engagement beyond discourse. Science \& Technology Studies 27(3): 90-110.

Davies SR (2017) Hackerspaces: Making the Maker Movement. Cambridge: Polity Press.

Douglas H (2004) The Irreducible Complexity of Objectivity. Synthese 138(3): 453-473.

Epstein S (1996) Impure science: AIDS, Activism, and the Politics of Knowledge. Berkeley and Los Angeles: University of California Press.

Funtowicz SO and Ravetz JR (1993) Science for the post-normal age. Futures 25(7): 739-755.

Goffman E (1959) The Presentation of Self in Everyday Life. New York: Doubleday Anchor Books.

Irwin EG, Culligan PJ, Fischer-Kowalski M, Law KL, Murtugudde R and Pfirman S (2018) Bridging barriers to advance global sustainability. Nature Sustainability 1(7): 324-326.

Jasanoff S (2003) Breaking the waves in science studies: Comment on H.M. Collins and Robert Evans, 'The third wave of science studies'. Social Studies of Science 33(3): 389-400.

Jasanoff S (2016) The Ethics of Invention: Technology and the Human Future. London: WW Norton \& Company.

Kera D (2012) Hackerspaces and DIYbio in Asia: connecting science and community with open data, kits and protocols. Journal of Peer Production 2(Jun): 1-8.

Kerr A and Garforth L (2016) Affective practices, care and bioscience: A study of two laboratories. The Sociological Review 64(1): 3-20.

Lindén L (2019) Love and Fear? Affect, Public Engagement and the Use of Facebook in HPV Vaccination Communication. Science \& Technology Studies, epub ahead of print: 1-17. Available at: https://sciencetechnologystudies.journal.fi/forthcoming/article/73095/40570 (accessed 17.4.2020).

Lorimer J (2008) Counting corncrakes: The affective science of the UK corncrake census. Social Studies of Science 38(3): 377-405.

Lynch M (2014) From normative to descriptive and back. In: Soler L, Zwart SD, Lynch M and Israel-Jost V (eds) Science After the Practice Turn in the Philosophy, History, and Social Studies of Science. New York, NY: Routledge, pp. 93-113.

Maxigas P (2012) Hacklabs and hackerspaces: tracing two genealogies. Journal of Peer Production (2).

Maybin J (2016) Producing Health Policy: Knowledge and Knowing in Government Policy Work. Basingstoke: Palgrave Macmillan. 
Myers N (2008) Molecular embodiments and the body-work of modeling in protein crystallography. Social Studies of Science 38(2): 163-199.

Rapley C (2012) Time to raft up. Nature 488(7413): 583-585.

Reed MS, Stringer LC, Fazey I, Evely AC and Kruijsen JHJ (2014) Five principles for the practice of knowledge exchange in environmental management. Journal of Environmental Management 146: 337-345.

Rip A (2003) Constructing expertise: In a third wave of science studies? Social Studies of Science 33(3): 419-434.

Saikkonen S (2019) Ability and authority? Studies on the constructedness and expansion of expertise in the contemporary public sphere. Helsinki: University of Helsinki. http://urn.fi/URN:ISBN:978-951-51-3412-7

Sharman A and Holmes J (2010) Evidence-based policy or policy-based evidence gathering? Biofuels, the EU and the 10\% target. Environmental Policy and Governance, 20(5), 309-321.

Smith K (2013) Beyond Evidence-Based Policy in Public Health: The interplay of ideas. Basingstoke: Palgrave Macmillan.

Taipale J (2019) Predefined criteria and interpretative flexibility in legal courts' evaluation of expertise. Public Understanding of Science 28(8): 883-896.

Turnhout E, Tuinstra W and Halffman W (2019) Environmental Expertise. Connecting Science, Policy, and Society. Cambridge: Cambridge University Press.

Verran H (1999) Staying true to the laughter in Nigerian classrooms. The Sociological Review 47: 136-156.

Wetherell M (2012) Affect and Emotion: A New Social Science Understanding. London: SAGE.

Wynne B (1992) Misunderstood misunderstanding: social identities and public uptake of science. Public Understanding of Science 1(3): 281-304.

Wynne B (1996) May the Sheep Safely Graze? A Reflexive View of the Expert-Lay Knowledge Divide. In: Lash S, Szerszynski B and Wynne B (eds) Risk, Environment and Modernity: Towards a New Ecology. London: SAGE, pp. 44-83.

Wynne B (2003) Seasick on the third wave? Subverting the hegemony of propositionalism: Response to Collins \& Evans (2002). Social Studies of Science 33(3): 401-417.

Åkerman M (2016) Contested expertise in navigating through wicked problems, keynote, Symposium of the Finnish Society for Science and Technology Studies, 2.6.2016, Helsinki. 